Supporting Information

\title{
Conformal Polymeric Multilayer Coatings on Sulfur Cathodes via the Layer-by-Layer Deposition for High Capacity Retention in Li-S Batteries
}

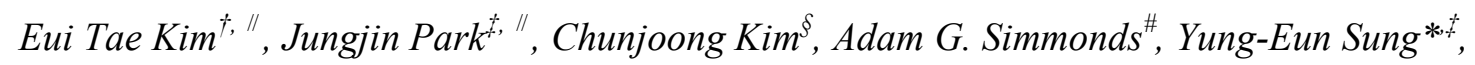
Jeffrey Pyun*\#, and Kookheon Char*广

\footnotetext{
${ }^{\dagger}$ The National Creative Research Initiative Center for Intelligent Hybrids, The WCU Program of Chemical Convergence for Energy \& Environment, School of Chemical \& Biological Engineering, Seoul National University, Seoul 08826, Korea.

${ }^{\ddagger}$ Center for Nanoparticle Research, Institute for Basic Science, School of Chemical \& Biological Engineering, Seoul National University, Seoul 08826, Korea.

${ }^{\S}$ Department of Materials Science and Engineering, Chungnam National University, Daejeon 34134, Korea

${ }^{\#}$ Department of Chemistry \& Biochemistry, University of Arizona, Tucson, AZ 85721, USA.
}

\section{Table of Contents}

\section{Experimental Details}

2. Surface Morphologies and Compositional analysis on the MultilayerCoated Cathodes.

3. Electrochemical Characterizations of the Multilayer-Coated Cathodes

\section{References}




\section{Experimental Details}

Materials: Polyallylamine hydrochloride (PAH, $\mathrm{Mw}=15000 \mathrm{~g} \mathrm{~mol}^{-1}$ ), polyacrylic acid $\left(\mathrm{PAA}, \mathrm{Mw}=50,000 \mathrm{~g} \mathrm{~mol}^{-1}\right)$, polyethylene oxide $\left(\mathrm{PEO}, \mathrm{Mw}=300,000 \mathrm{~g} \mathrm{~mol}^{-1}\right)$, lithium nitrate $\left(\mathrm{LiNO}_{3}\right)$, and bis(trifluoromethane)sulfonamide lithium salt (LiTFSI) were purchased from Sigma-Aldrich. The sulfur powder $\left(\mathrm{S}_{8}, 325 \mathrm{mesh}\right)$ was purchased from Alfa Aesar. Super P carbon and polyvinylidene fluoride (pvdf) were provided from SK innovation. dioxolane (DOL) and dimethyl ether (DME) were purchased from PanaxEtec.

Preparation of substrates: The slurry mixture for $\mathrm{S}_{8}$ cathode was prepared by mortar mixing of $\mathrm{S}_{8}(60 \mathrm{wt} . \%)$, super P (20 wt.\%), and pvdf (20 wt.\%), and then casted on an Al foil using doctor blade method, followed by drying in a vacuum oven for 12 hours. The carbon+binder substrates were prepared by the same procedure as described above for the $\mathrm{S}_{8}$ cathode, but without $\mathrm{S}_{8}$ powder inclusion. The $\mathrm{S}_{8}$-only substrate was fabricated by spin-casting of $\mathrm{S}_{8}$ dissolved in carbon disulfide $\left(\mathrm{CS}_{2}\right)$ solution on gold substrate.

Layer-by-layer deposition: The polymer solutions for layer-by-layer (LbL) deposition were prepared by dissolving polymers in $18 \mathrm{M} \Omega$ Milli-Q wtater $\left(1 \mathrm{mg} \mathrm{mL}^{-1}\right)$, and $\mathrm{pH}$ of each solution was adjusted using $0.1 \mathrm{M}$ of $\mathrm{HCl}$ and $\mathrm{NaOH}$. The rinsing solutions corresponding to each polymer solution with the same $\mathrm{pH}$ were prepared with Milli-Q water. LiTFSI $(0.1 \mathrm{M})$ was added to all polymer and rinsing solutions. For the deposition of priming bilayer, the $\mathrm{S}_{8}$ cathodes were initially dipped into PAH $(\mathrm{pH}=7.5)$ solution for $5 \mathrm{~min}$ and then spun at 1500 rpm for $30 \mathrm{~s}$, followed by rinsing with the Milli-Q water of the same $\mathrm{pH}$ at the same rpm. The PAA $(\mathrm{pH}=3.5)$ solution was spun at the same condition, and then washed with the rinsing solution with the same $\mathrm{pH}$. The layer-by-layer deposition was conducted on top of the priming bilayer with PEO $(\mathrm{pH}=2.5)$ and PAA $(\mathrm{pH}=2.5)$, by dipping for $5 \mathrm{~min}$ in each polymer solution and $1 \mathrm{~min}$ in rinsing solution, respectively. The cycle was repeated for the required number of bi-layers. After deposition, the cathodes were dried overnight in vacuum oven at $50^{\circ} \mathrm{C}$.

Morphology Characterization: Water contact angles were measured using a DE/DSA100 contact angle analyzer (Fruss Inc.). Scanning electron microscopy (SEM) images were obtained with JSM-6701F (JEOL). X-ray photoelectron spectroscopy (XPS) was conducted using Axis-HSi (Kratos) with $\mathrm{Mg} / \mathrm{Al}$ dual anode at $15 \mathrm{kV}$ and $10 \mathrm{~mA}$.

Electrochemical Characterization: All cathodes were punched into circular disks (diameter $\sim 11 \mathrm{~mm}$ ) and assembled in a 2032 type coin cell. The loading levels of sulfur are up to $\sim 1.0$ $\mathrm{mg} \mathrm{cm}$. The electrolyte was prepared with LiTFSI $(1.0 \mathrm{M})$, and with or without $\operatorname{LiNO}_{3}(0.1$ 
M) in DOL and DME 1:1 volume ratio mixture. Electrochemical properties were measured with a WBC300 cycler (Won-A Tech, Korea). The potential window was fixed to 1.7 V-2.8 $\mathrm{V}$ vs. $\mathrm{Li}^{+} / \mathrm{Li}$. The electrochemical impedance spectroscopy (EIS) was performed at opencircuit voltage between $100 \mathrm{kHz}$ to $100 \mathrm{mHz}$ with fluctuations of $10 \mathrm{mV}$.

\section{Surface Morphologies and Compositional analysis on the Multilayer- Coated Cathodes.}
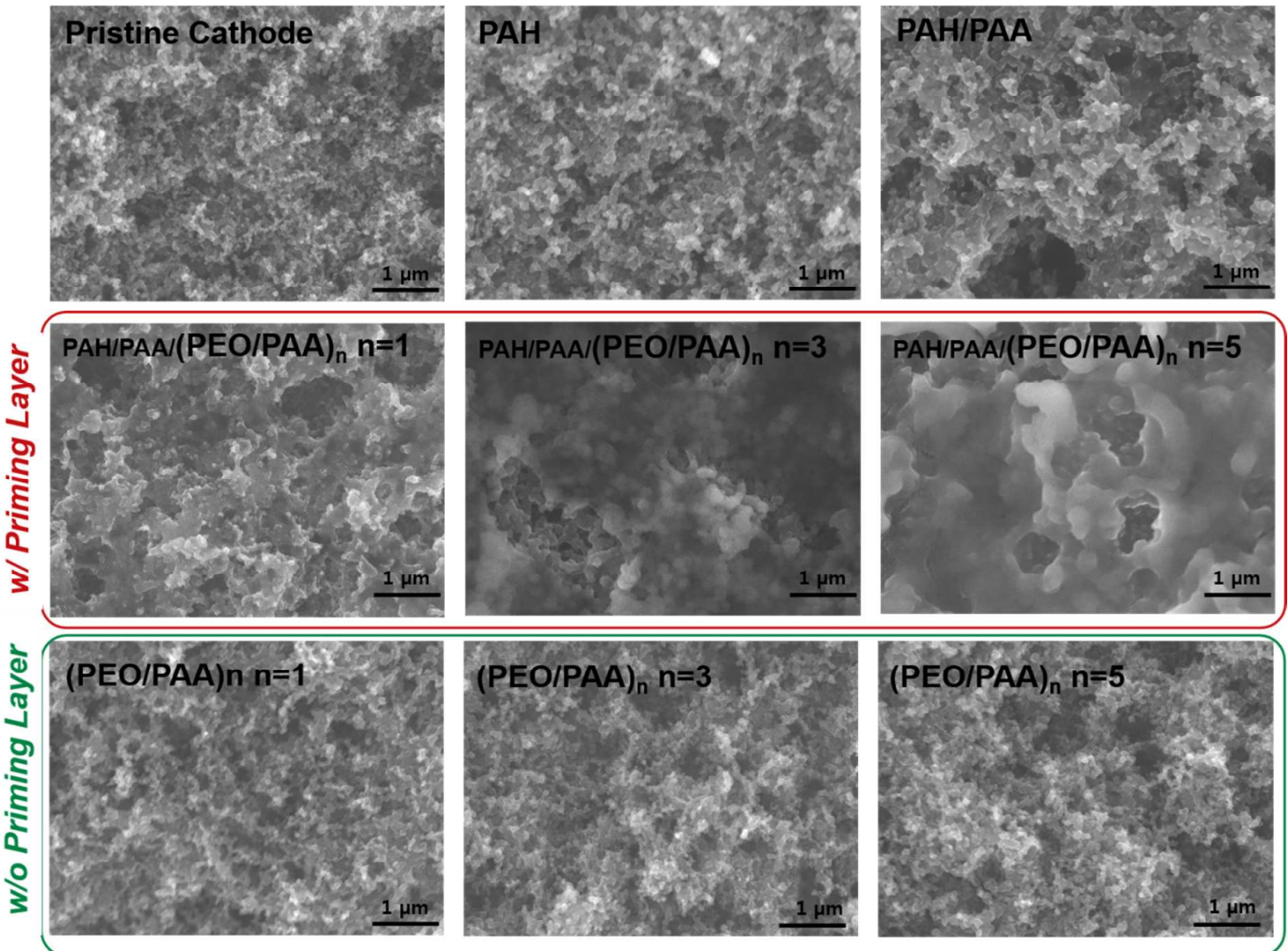

Figure S1. SEM images of sulfur cathodes showing the morphological changes during the deposition of (PEO/PAA $)_{n}, n=1,3$, and 5, with and without the priming layer of (PAH/PAA). 


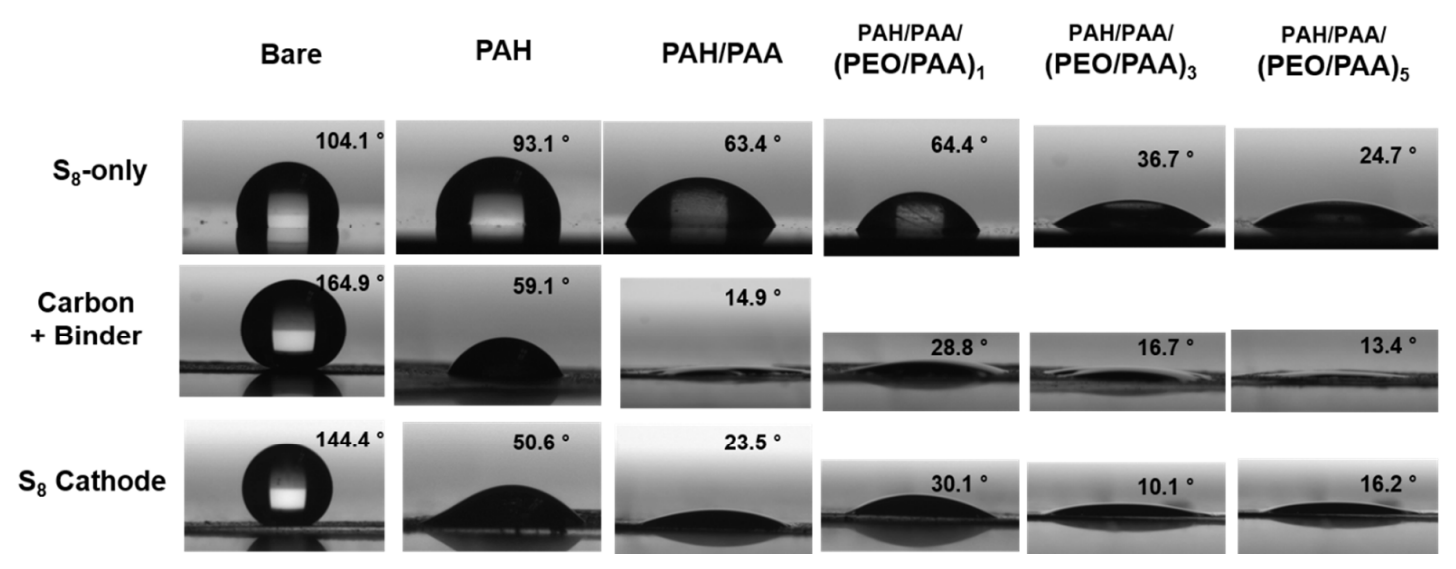

Figure S2. Photo images of water contact angle measurements showing the gradual decrease in contact angle as a function of adsorbed polymer layers placed on the substrates of $\mathrm{S}_{8}$-only, carbon+binder, and $\mathrm{S}_{8}$ cathode.

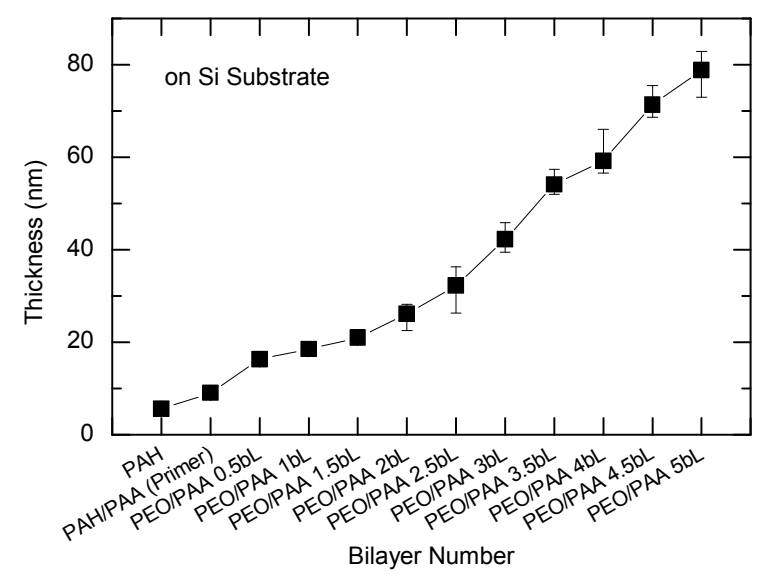

Figure S3. The growth of multilayer film thickness as a function of bilayer number during the $\mathrm{LbL}$ deposition of $\mathrm{PAH} / \mathrm{PAA} /(\mathrm{PEO} / \mathrm{PAA})_{\mathrm{n}}$ multilayers on Si wafer substrates.
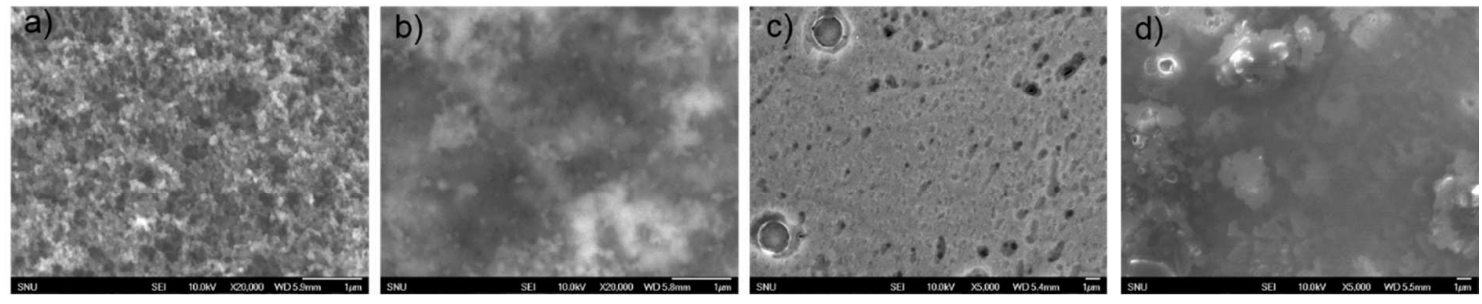

Figure S4. SEM images of a) an as-prepared carbon+binder substrate, b) a $\mathrm{PAH} / \mathrm{PAA} /(\mathrm{PEO} / \mathrm{PAA})_{5}$ multilayer coated on a carbon+binder substrate, c) a bare $\mathrm{S}_{8}-$ only substrate, d) $\mathrm{PAH} / \mathrm{PAA} /(\mathrm{PEO} / \mathrm{PAA})_{5}$ multilayer coated on a $\mathrm{S}_{8}$-only substrate. 

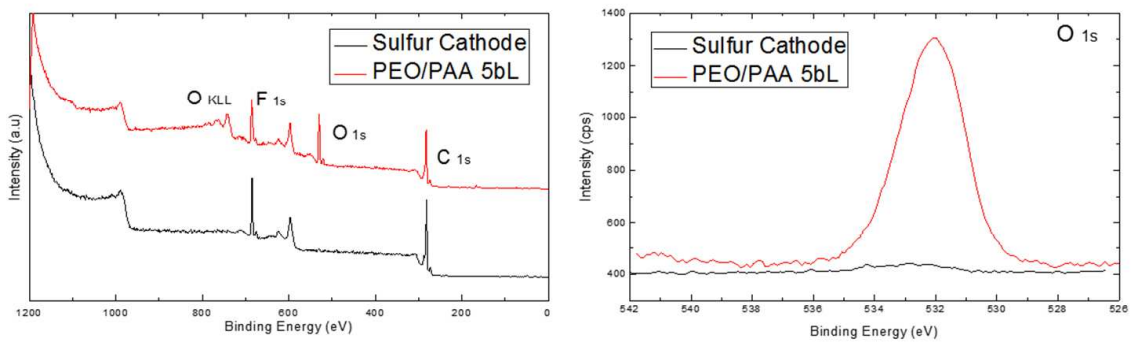

Figure S5. XPS spectra of a pristine $\mathrm{S}_{8}$ cathode and a PAH/PAA/(PEO/PAA $)_{5}$ multilayercoated $\mathrm{S}_{8}$ cathode.
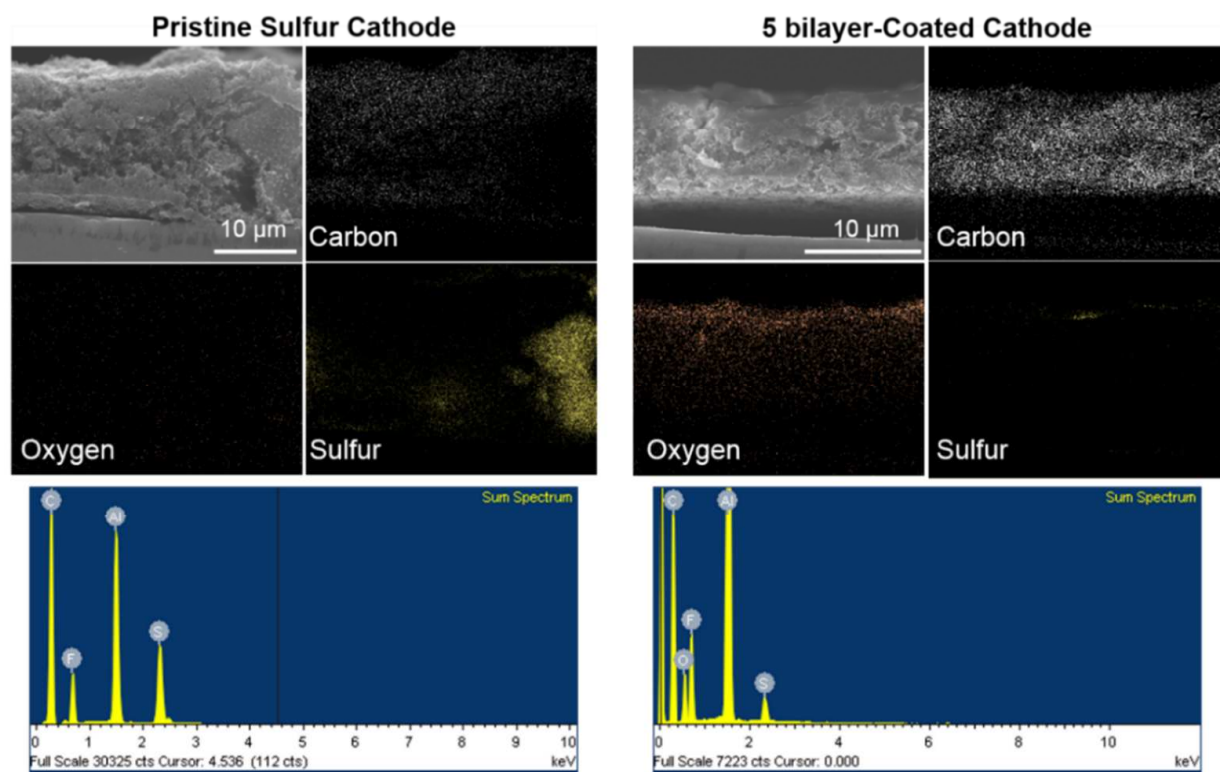

Figure S6. Elemental maps and EDS spectra for a pristine $\mathrm{S}_{8}$ cathode and a $\mathrm{PAH} / \mathrm{PAA} /(\mathrm{PEO} / \mathrm{PAA})_{5}$ multilayer-coated $\mathrm{S}_{8}$ cathode.

\begin{tabular}{lcc}
\hline $\begin{array}{l}\text { Element } \\
{[\mathrm{wt} \%]}\end{array}$ & $\begin{array}{c}\text { Bare } \\
\text { Cathode }\end{array}$ & $\begin{array}{c}\text { PEO/PAA 5 bi-layer } \\
\text { Cathode }\end{array}$ \\
\hline $\mathrm{C}$ & 72.41 & 53.07 \\
$\mathrm{O}$ & - & 10.72 \\
$\mathrm{~F}$ & 15.07 & 18.67 \\
$\mathrm{Al}$ & 7.95 & 16.54 \\
$\mathrm{~S}$ & 4.24 & 1.00 \\
Totals & 99.67 & 100.00
\end{tabular}

Table S1. Weight fraction of elements estimated from EDS spectra on a pristine $\mathrm{S}_{8}$ cathode and a $\mathrm{PAH} / \mathrm{PAA} /(\mathrm{PEO} / \mathrm{PAA})_{5}$ multilayer-coated $\mathrm{S}_{8}$ cathode. 


\section{Electrochemical Characterizations of the Multilayer Coated Cathodes}

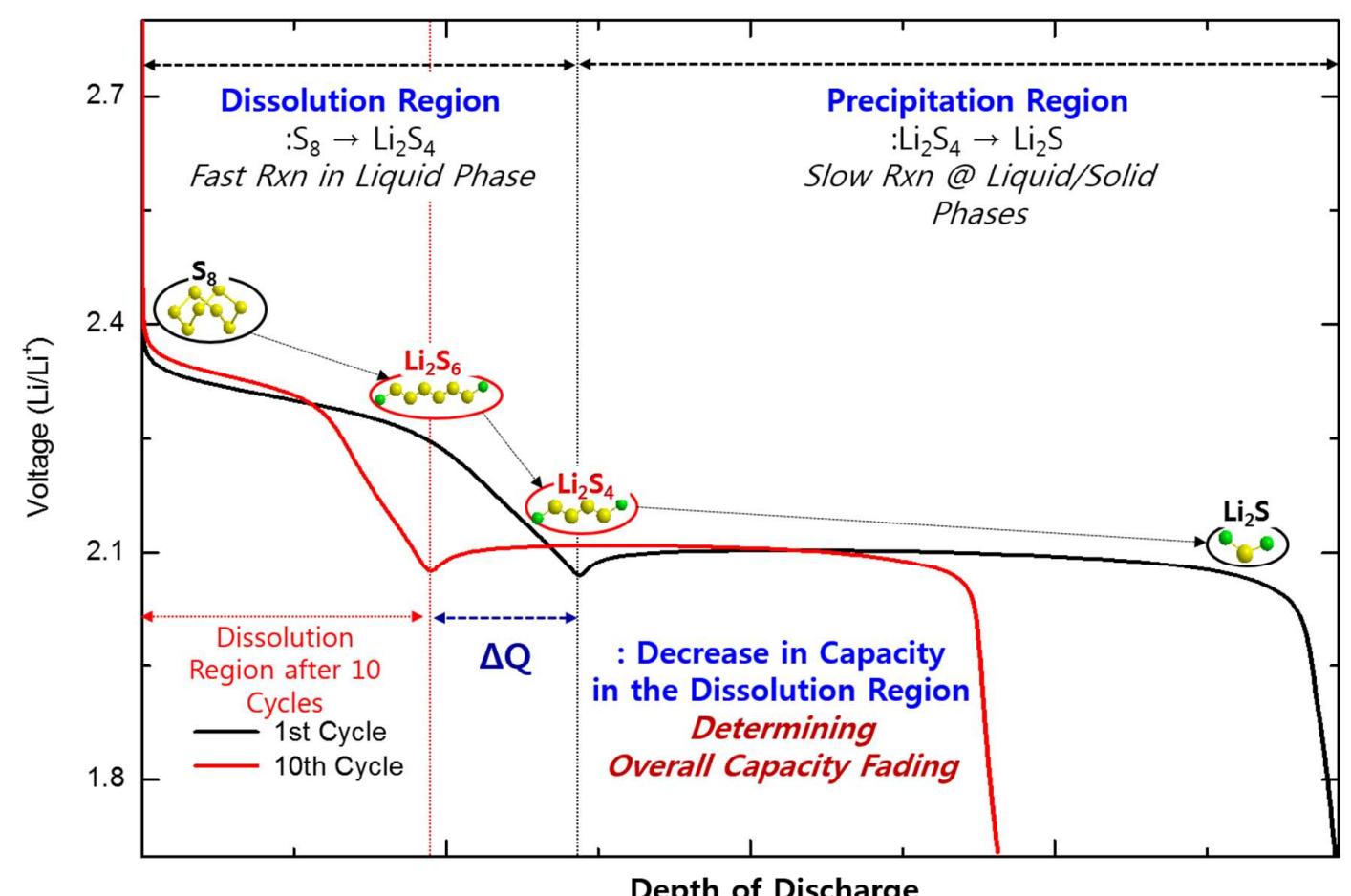

A. Manthiram et al., Nature Comm. 2013, 4, 2985

Figure S7. A schematic description of the specific capacity decrease in the dissolution region, indicated with the discharge voltage profile. ${ }^{1}$

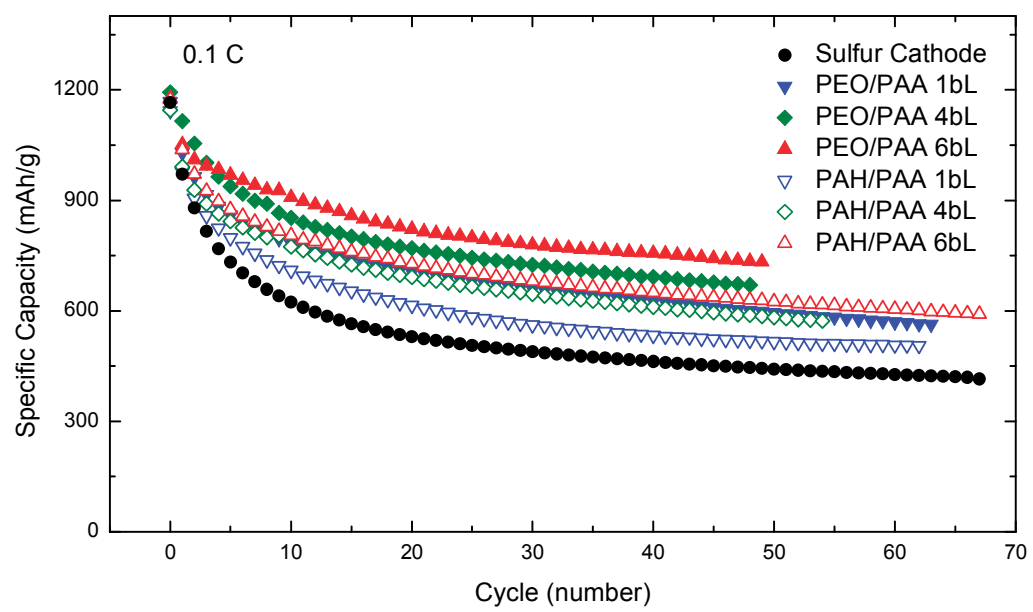

Figure S8. Cyclic performance at $0.1 \mathrm{C}$ with a pristine $\mathrm{S}_{8}$ cathode and the multilayer-coated cathodes with PAH/PAA/(PEO/PAA $)_{n}$, and $(\mathrm{PAH} / \mathrm{PAA})_{\mathrm{n}}(\mathrm{n}=1,4$, and 6). 

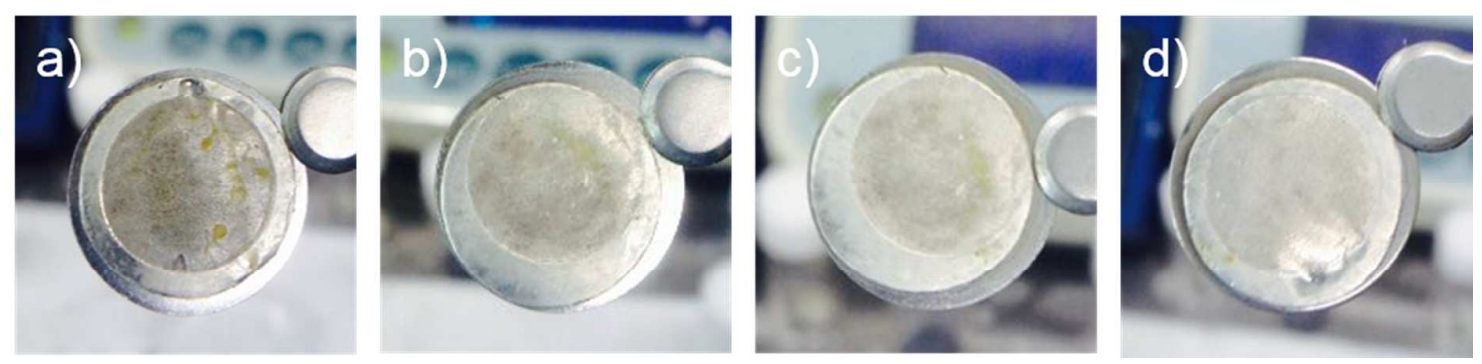

Figure S9. Photo images of Li anodes disassembled after 10 cycles with: a) a pristine $\mathrm{S}_{8}$ cathode and PAH/PAA/(PEO/PAA $)_{n}$ multilayer-coated cathodes: b) $\left.n=1, c\right) n=3$, and d) $n$ $=5$.
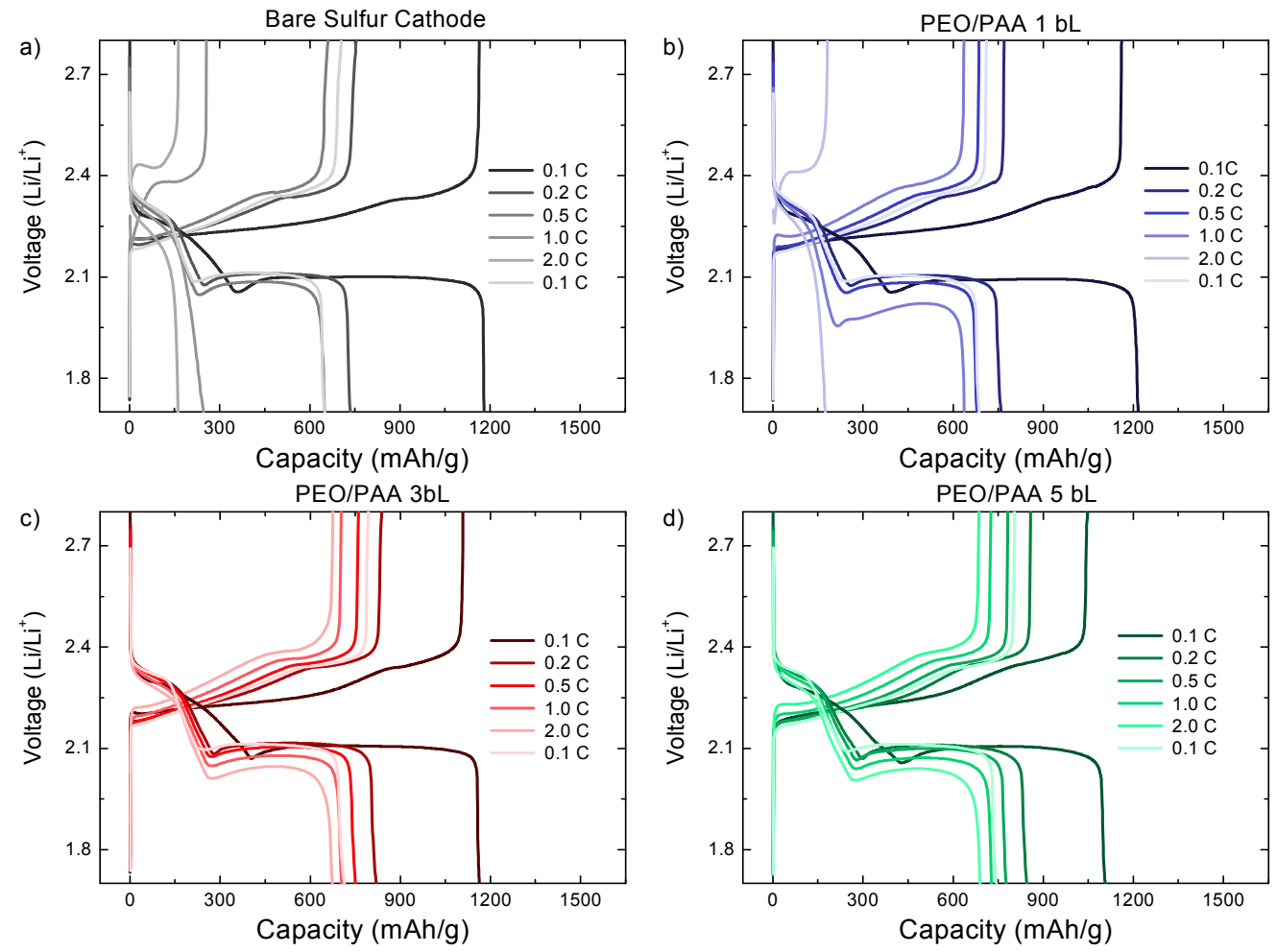

Figure S10. Charge-discharge voltage profiles with different $\mathrm{C}$-rates varying from $0.1 \mathrm{C}$ to 2.0 C of: a) a pristine $\mathrm{S}_{8}$ cathode and $\mathrm{PAH} / \mathrm{PAA} /(\mathrm{PEO} / \mathrm{PAA})_{\mathrm{n}}$ multilayer-coated cathodes: $\left.\mathrm{b}\right)$ $\mathrm{n}=1, \mathrm{c}) \mathrm{n}=3$, and d) $\mathrm{n}=5$. 


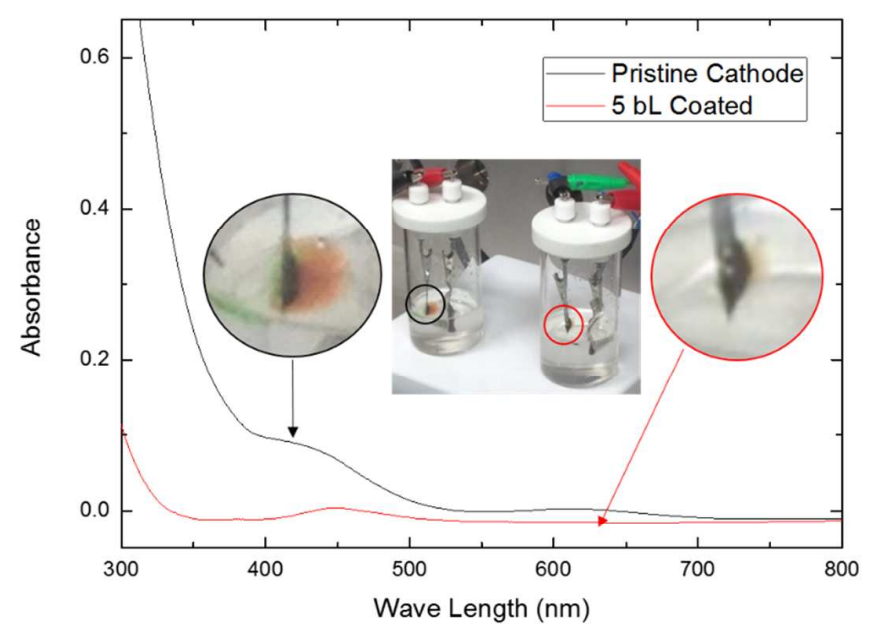

Figure S11. UV-Vis spectra and photo images of beaker cells (electrodes immersed in excess electrolyte solutions), taken at 5 min after applying a constant voltage at $1.5 \mathrm{~V}$ to the beaker cells, assembled with a pristine $\mathrm{S}_{8}$ cathode (left, black), and a PAH/PAA/(PEO/PAA) multilayer-coated cathode (right, red). The absorption bands in the electrolyte solution with a pristine $\mathrm{S}_{8}$ cathode are believed to originate from $\mathrm{S}_{\mathrm{x}}{ }^{2-}(\mathrm{x}=4 \sim 8)$ and $\mathrm{S}_{3} \cdot{ }^{-}$assigned to $430 \mathrm{~nm}$ and $620 \mathrm{~nm}$ peaks, respectively. ${ }^{2-5}$

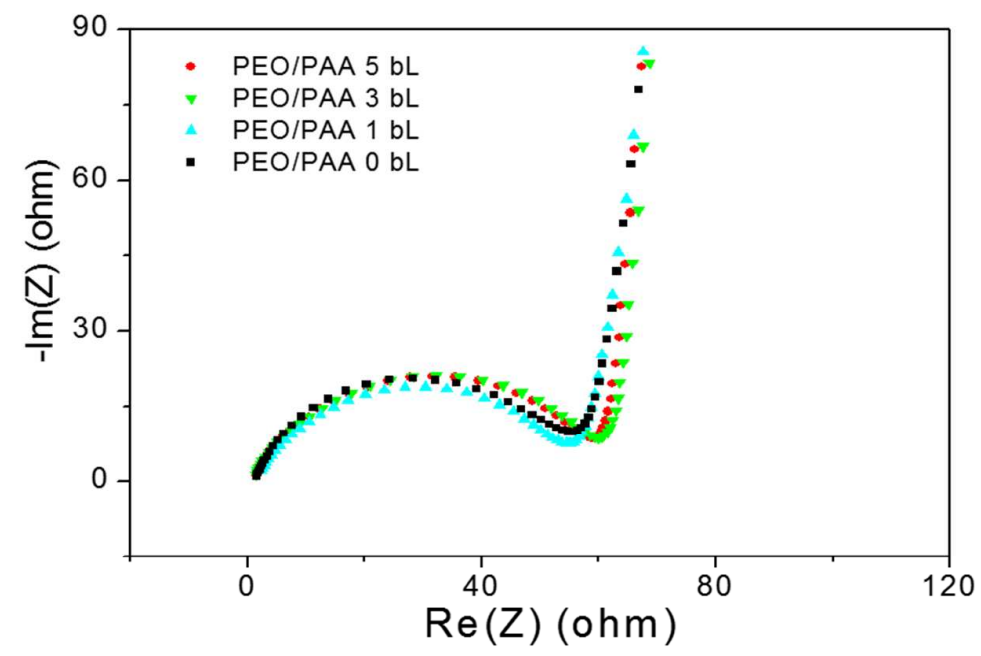

Figure S12. Electrochemical impedance spectroscopic (EIS) data on a pristine $\mathrm{S}_{8}$ cathode and PAH/PAA/(PEO/PAA $)_{\mathrm{n}}$ multilayer-coated cathodes $(\mathrm{n}=1,3$, and 5). 
a)

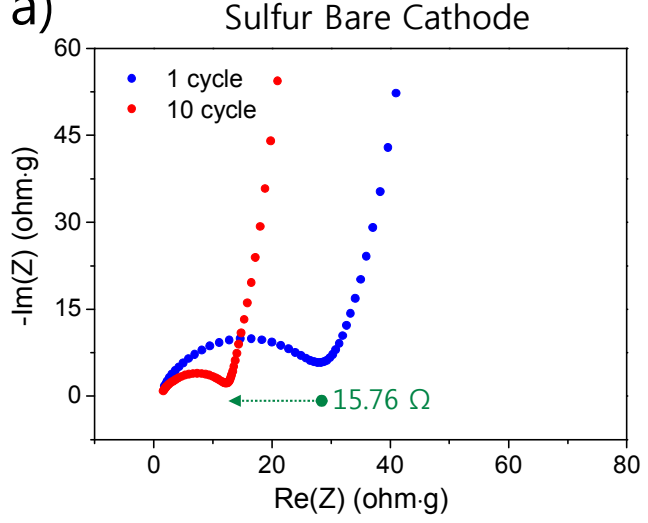

c)

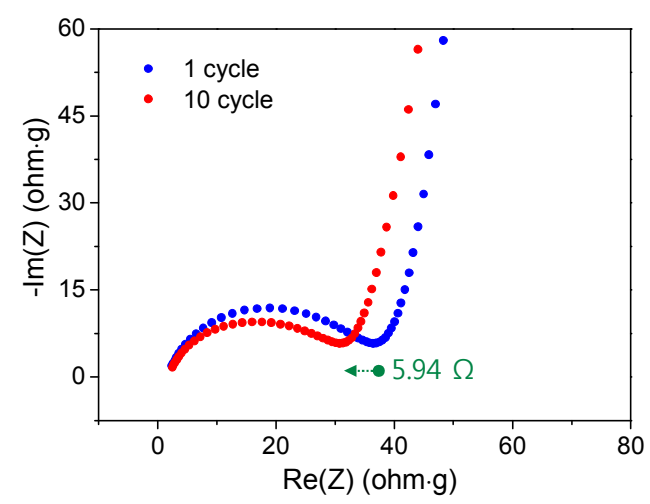

b)

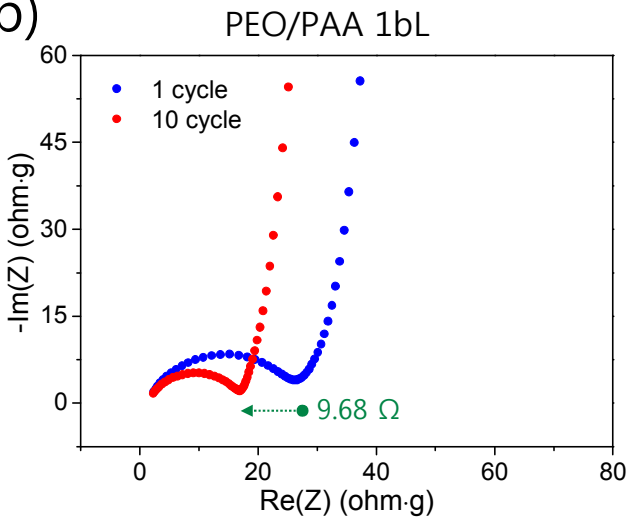

d)

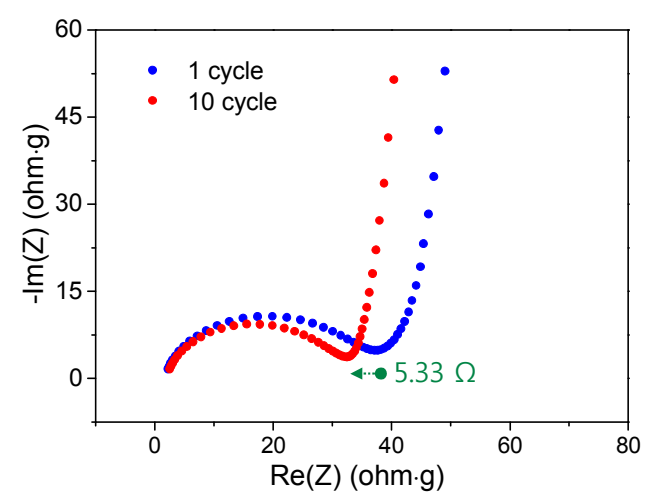

Figure S13. EIS data measured after initial and 10 cycles on: a) a pristine $\mathrm{S}_{8}$ cathode and $\mathrm{PAH} / \mathrm{PAA} /(\mathrm{PEO} / \mathrm{PAA})_{\mathrm{n}}$ multilayer-coated cathodes: b) $\left.\mathrm{n}=1, \mathrm{c}\right) \mathrm{n}=3$, and d) $n=5$.
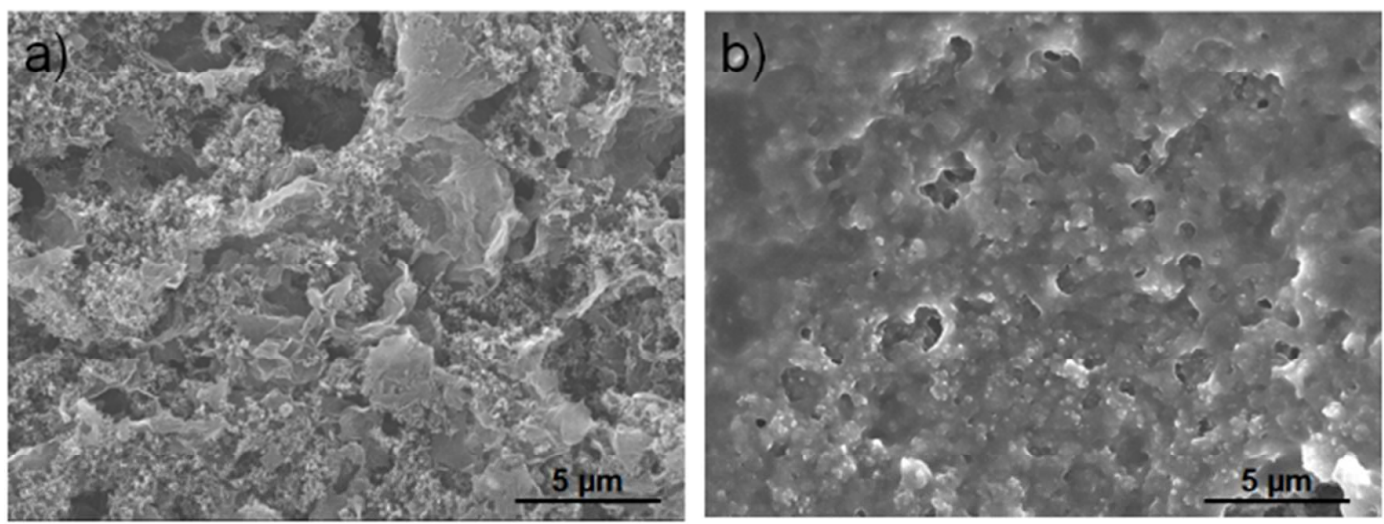

Figure S14. SEM images of: a) a pristine $\mathrm{S}_{8}$ cathode and b) a PAH/PAA/(PEO/PAA) $)_{5}$ multilayer-coated cathode after 10 cycles of discharge/charge at $0.5 \mathrm{C}$. 


\section{References}

(1) Su, Y. S.; Fu, Y. Z.; Cochell, T.; Manthiram, A. Nat. Commun. 2013, 4, 2985.

(2) Bonnaterre, R.; Cauquis, G. J. Chem. Soc., Chem. Commun. 1972, 5, 293-294.

(3) Kawase, A.; Shirai, S.; Yamoto, Y.; Arakawa, R.; Takata, T. Phys. Chem. Chem. Phys. 2014, $15,9344-9350$.

(4) Cuisinier, M.; Hart, C.; Balasubramanian, M.; Garsuch, A.; Nazar, L. F. Adv. Energy Mater. 2015, 5, 1401801.

(5) Rauh, R. D.; Shuker, R. S.; Marston, J. M.; Brummer, S. B. J. Inorg. Nucl. Chem. 1977, 39, 1761-1766. 